\title{
Penentuan Proporsi Keuntungan untuk Kontrak Asuransi Jiwa Dwiguna Unit Link dengan Menggunakan Metode Annual Ratchet
}

\author{
Yopi SAPuTRA, NeVA SATYAHADEWI, HENDRA PERDANA \\ ${ }^{1}$ Mahasiswa Program S1 Program Studi Statistika FMIPA Universitas Tanjungpura \\ 2,3Program Studi Statistika FMIPA Universitas Tanjungpura \\ Email: neva.satya@gmail.com
}

\begin{abstract}
ABSTRAK
Asuransi jiwa dwiguna unit link merupakan asuransi yang menggabung keseluruhan asuransi jiwa tradisional dwiguna dengan asuransi modern unit link yang menyediakan perlindungan dan investasi. Salah satu metode yang digunakan dalam kontrak asuransi jiwa unit link yaitu metode pengindeksan dengan tingkat partisipasi. Metode pengindeksan yang digunakan adalah annual ratchet, dimana tingkat partisipasi dievaluasi dari tahun ke tahun. Data yang digunakan dalam penelitian ini adalah data saham penutupan harian PT. Telkom tahun 2012 dan suku bunga Bank Indonesia bulan Januari tahun 2013. Data probabilitas hidup mengikuti Tabel Mortalita Indonesia tahun 2011. Hasil penelitian ini diperoleh proporsi keuntungan menggunakan desain compound ratchet sebesar 56.09\% untuk nasabah dan $43.91 \%$ untuk perusahaan. Sedangkan proporsi keuntungan menggunakan desain simple ratchet sebesar $61.27 \%$ untuk nasabah dan $38.73 \%$ untuk perusahaan.
\end{abstract}

Kata Kunci: Unit link, Annual Ratchet, Proporsi Keuntungan.

\section{PENDAHULUAN}

Asuransi adalah suatu pemindahan risiko dimana penanggung (insurer) mengikat diri kepada tertanggung (insured) dengan menerima premi[1]. Asuransi unit link mengandung investasi, dimana setiap saat nilainya bervariasi sesuai dengan nilai aset investasi tersebut. Saat harga saham drastis turun maka manfaatnya juga ikut turun. Cara mengatasi hal tersebut perusahaan asuransi memberikan suatu manfaat minimum (floor) dan tertanggung akan memperoleh manfaat sebesar harga kesepakatan pada kontrak. Sebaliknya jika harga saham drastis naik, maka manfaatnya juga ikut naik yang bisa mengakibatkan perusahaan. Hal ini dapat diatasi dengan memberikan batasan manfaat maksimum (cap) yang akan diperoleh tertanggung. Tertanggung atau ahli waris akan memperoleh manfaat maksimum sebesar nilai cap-nya saat itu dan manfaat minimum sebesar nilai floor yang telah disepakati[2].

Perhitungan manfaat yang diperoleh tertanggung pada unit link dapat menggunakan metode pengindeksan. Ada tiga metode pengindeksan yang dapat digunakan untuk menghitung manfaat asuransi unit link yaitu point to point, annual ratchet, dan high water mark. Metode pengindeksan yang digunakan dalam penelitian ini adalah annual ratchet, dimana indeks partisipasi dievaluasi dari tahun ke tahun (annual)[3].

Metode annual ratchet terdiri dari dua jenis desain, yaitu simple ratchet dan compound ratchet. Keuntungan investasi pada simple ratchet hanya diperhitungkan satu kali untuk satu periode terhadap jumlah pokok yang besarnya tetap. Sedangkan pada compound ratchet keuntungan investasi periode sebelumnya akan diikutsertakan untuk menghitung keuntungan pada periode berikutnya. 


\section{TEORI}

\section{Volatilitas Return Data Saham}

Volatilitas return saham yang dinyatakan dengan $\sigma$ merupakan standar deviasi dari return saham pada periode tahunan. Volatilitas ini digunakan untuk mengukur tingkat risiko dari suatu saham. Nilai volatilitas yang tinggi menunjukkan bahwa harga saham berubah (naik dan turun) dengan range yang sangat lebar. Sedangkan volatilitas dikatakan rendah jika harga saham jarang berubah atau cenderung konstan.

Salah satu metode untuk mengestimasi volatilitas return saham adalah volatilitas historis, yaitu volatilitas yang dihitung berdasarkan pada harga-harga masa lalu. Pendekatan volatilitas merupakan deviasi standar dari return saham tahunan[3].

$\sigma=\sqrt{\text { jumlah hari perdagangan } \times\left[\frac{\sum_{t=1}^{n}(R(t)-\overline{R(t)})^{2}}{n-1}\right]}$

\section{Asuransi Jiwa Dwiguna (Endowment Insurance)}

Asuransi jiwa dwiguna $n$ tahun dapat dipandang sebagai kombinasi dari asuransi jiwa berjangka $n$ tahun dan asuransi jiwa dwiguna murni $n$ tahun. Oleh karena itu, pada asuransi dwiguna manfaat kematian akan diberikan apabila tertanggung meninggal sebelum $n$ tahun[4].

Fungsi manfaat (benefit), $b_{k+1}$, yaitu jumlah pembayaran manfaat dimana indeks $k+1$ menyatakan sisa usia dari nasabah. $V_{k+1}$, yaitu faktor diskonto suku bunga yang ditetapkan untuk periode dari waktu pengembalian pembayaran sampai waktu diterbitkannya polis. Nilai waktu sekarang (present value) pada saat polis diterbitkan dari pembayaran manfaat asuransi dinotasikan dengan, $Z_{k+1}$, yaitu:

$z_{k+1}=b_{k+1} v_{k+1}$

Asuransi jiwa dwiguna $\mathrm{n}$ tahun memberikan manfaat sebesar 1 satuan pada akhir tahun kematian, diberikan oleh[4]:

$$
\begin{array}{ll}
b_{k+1} & = \begin{cases}1 & , k=0,1,2, \ldots, n-1 \\
1 & , k=n, n+1, \ldots\end{cases} \\
v_{k+1} & = \begin{cases}v^{k+1} & , k=0,1,2, \ldots, n-1 \\
v^{n} & , k=n, n+1, \ldots\end{cases} \\
Z & = \begin{cases}1\left(v^{k+1}\right) & , k=0,1,2, \ldots, n-1 \\
1\left(v^{n}\right) & , k=n, n+1, \ldots\end{cases}
\end{array}
$$

Nilai sekarang aktuaria untuk asuransi ini diberikan sebagai berikut:

$$
A_{x: n}=E[Z]=\left[\sum_{k=0}^{n-1}\left(v^{k+1}\right)\left({ }_{k} p_{x}\right)\left(q_{x+k}\right)\right]+\left[\left(v^{n}\right)\left({ }_{n} p_{x}\right)\right]
$$

${ }_{k} p_{x}$ adalah probabilitas seseorang yang sekarang berusia $x$ tahun akan hidup sampai $k$ tahun kemudian. $q_{x+k}$ adalah probabilitas seseorang yang sekarang berusia $(x+k)$ tahun akan meninggal satu tahun kemudian.

\section{Struktur Manfaat dengan Metode Annual Ratchet}

Metode pengindeksan annual ratchet terdiri dari dua jenis desain, yaitu simple ratchet dan compound ratchet. Pada simple ratchet, keuntungan hanya diperhitungkan satu kali untuk satu 
periode terhadap jumlah pokok yang besarnya tetap. Sedangkan pada compound ratchet, keuntungan periode sebelumnya akan diikutsertakan untuk menghitung keuntungan pada periode berikutnya. Sehingga dari periode ke periode keuntungan menjadi semakin besar, yang merupakan akumulasi dari penambahan keuntungan periode sebelumnya[5].

Struktur manfaat dengan desain compound ratchet:

$$
\begin{aligned}
B_{C R}(t) & =\max \left(\beta(1+g)^{t}, C R\right)=C R+\max \left(\beta(1+g)^{t}-C R, 0\right) \\
C R & =\prod_{t=1}^{n}(1+\min (\max (\alpha(R(t)-1), f), c))
\end{aligned}
$$

Struktur manfaat dengan desain simple ratchet:

$$
\begin{aligned}
B_{S R}(t) & =\max \left(\beta(1+g)^{t}, S R\right)=S R+\max \left(\beta(1+g)^{t}-S R, 0\right) \\
S R & =1+\sum_{t=1}^{n} \min (\max (\alpha(R(t)-1), f), c)
\end{aligned}
$$

dengan:

$(R(t)-1)=$ Keuntungan yang diperoleh pada waktu $t$

$\alpha \quad=$ Proporsi keuntungan

$c \quad=$ Tingkat suku bunga cap (batas atas)

$f \quad=$ Tingkat suku bunga floor (batas bawah)

$g \quad=$ Tingkat suku bunga garansi

$n \quad$ = Jangka waktu kontrak

$\beta \quad=$ Besarnya persentase pengembalian

Berdasarkan Persamaan (5), nilai kontrak pada waktu sekarang untuk compound ratchet ratchet adalah:

$$
\begin{aligned}
& V_{C R}(t, n)=\left\{\begin{array}{cc}
e^{-r n} E\left[\left(\beta(1+g)^{n}\right)\right] & , C R<\beta(1+g)^{n} \\
e^{-r n} E[C R] & , C R \geq \beta(1+g)^{n}
\end{array}\right. \\
& V_{C R}(t, n)=\left\{\begin{array}{cc}
e^{-r n}\left(\beta(1+g)^{n}\right) & , C R<\beta(1+g)^{n} \\
e^{-r n} \prod_{t=1}^{n}\left(\begin{array}{c}
(1+f) \Phi\left(-d_{2}\right)+(1-\alpha)\left(\Phi\left(d_{2}\right)-\left(d_{4}\right)\right)+ \\
\alpha \exp (r)\left(\Phi\left(d_{1}\right)-\Phi\left(d_{3}\right)\right)+(1+c) \Phi\left(d_{4}\right)
\end{array}\right), C R \geq \beta(1+g)^{n}
\end{array}\right.
\end{aligned}
$$

Berdasarkan Persamaan (6), nilai kontrak pada waktu sekarang untuk simple ratchet adalah:

$$
\begin{aligned}
V_{S R}(t, n) & =\left\{\begin{array}{cl}
e^{-r n} E\left[\left(\beta(1+g)^{n}\right)\right] & , S R<\beta(1+g)^{n} \\
e^{-r n} E[S R] & , S R \geq \beta(1+g)^{n}
\end{array}\right. \\
& =\left\{\begin{array}{c}
e^{-r n}\left(\beta(1+g)^{n}\right) \\
e^{-r n} \prod_{t=1}^{n}\left(\begin{array}{c}
(1+f) \Phi\left(-d_{2}\right)+(1-\alpha)\left(\Phi\left(d_{2}\right)-\left(d_{4}\right)\right)+ \\
\alpha \exp (r)\left(\Phi\left(d_{1}\right)-\Phi\left(d_{3}\right)\right)+(1+c) \Phi\left(d_{4}\right)
\end{array}\right), C R \geq \beta(1+g)^{n}
\end{array}\right.
\end{aligned}
$$

dengan: 


$$
\begin{array}{ll}
d_{1}=\frac{\left(\ln (1 /(1+f / \alpha))+r+\sigma^{2} / 2\right)}{\sigma} & , d_{2}=d_{1}-\sigma \\
d_{3}=\frac{\ln (1 /(1+c / \alpha))+r+\sigma^{2} / 2}{\sigma} & , d_{4}=d_{3}-\sigma
\end{array}
$$

$\Phi$ adalah fungsi distribusi kumulatif normal baku.

\section{Premi Tunggal Bersih untuk Kontrak Asuransi Jiwa Dwiguna Unit Link Menggunakan Metode Annual Ratchet}

Nilai sekarang aktuaria dari asuransi jiwa dwiguna unit link untuk jangka waktu $n$ tahun adalah sebagai berikut[4]:

$$
A_{x: n}=\left[\sum_{k=0}^{n-1} E\left[B(k+1) e^{-r(k+1)}\right]\left({ }_{k} p_{x}\right)\left(q_{x+k}\right)\right]+E\left[B(n) e^{-r n}\right]_{n} p_{x}
$$

Nilai sekarang aktuaria adalah sebagai berikut:

$$
A_{x: n}=\left[\sum_{k=0}^{n-1} V_{C R / S R}(k, k+1)\left({ }_{k} p_{x}\right)\left(q_{x+k}\right)\right]+V_{C R / S R}(n-1, n)_{n} p_{x}
$$

Premi tunggal bersih untuk kontrak asuransi jiwa dwiguna unit link dengan menggunakan metode Annual Ratchet adalah:

$$
P\left(A_{x: n}\right)=\left[\sum_{k=0}^{n-1} V_{C R / S R}(k, k+1)\left({ }_{k} p_{x}\right)\left(q_{x+k}\right)\right]+V_{C R / S R}(n-1, n)_{n} p_{x}
$$

\section{STUDI KASUS}

Seorang pria (tertanggung) berusia 25 tahun akan membeli sebuah kontrak asuransi jiwa dwiguna unit link 5 tahun dengan investasi membeli saham pada tanggal 2 Januari 2012. Investasi dalam bentuk kontrak asuransi unit link dengan saham yang dipilih adalah saham Telkom dengan harga Rp.1.410,00 perlembar saham. Kesepakatan kedua belah pihak dalam hal ini tertanggung dan penanggung adalah tingkat pengembalian (garansi) sebesar 90\% dari nilai premi yang dibayarkan.

Tingkat suku bunga garansi yang digunakan sebesar 5\% dari return yang diperoleh selama periode kontrak asuransi. Nilai batas bawah (floor rate) dari keuntungan investasi adalah sebesar $0 \%$ serta batas atas (cap rate) dari keuntungan investasi adalah sebesar $15 \%$. Volatilitas return harga saham dihitung berdasarkan data harian harga penutupan saham Telkom selama tahun 2012 dari tanggal 2 Januari 2012 sampai 28 Desember 2012, yaitu sebesar 0.2713 .

Data probabilitas hidup mengikuti Tabel Mortalita Indonesia II tahun 2011. Suku bunga bebas risiko mengacu pada suku bunga Sertifikat Bank Indonesia yang dikeluarkan pada tanggal 10 Januari 2013 untuk jangka waktu satu tahun sebesar 5.75\%. Pria tersebut ingin mengetahui proporsi pembagian keuntungan pada asuransi jiwa dwiguna unit link dengan menggunakan metode annual ratchet. Penyelesaian kasus ini menggunakan bantuan software $\mathrm{R}$ versi 3.4.3 dan Microsoft Excel.

Berdasarkan informasi tersebut, maka perhitungan nilai premi tunggal asuransi jiwa dwiguna tradisional menggunakan Persamaan (4), yaitu:

$$
\begin{aligned}
A_{25: 5 !} & =\left(\sum_{k=0}^{5-1} v_{k}^{k+1} p_{25} q_{25+k}\right)+v_{5}^{5} p_{25} \\
& =0.00302+0.56224=0.56526 \\
P\left(A_{25: 5}\right) & =\text { Benefit } *\left(A_{25: 5}\right) \\
& =100 \text { juta }(0.56526)=\text { Rp. } 56,526,000
\end{aligned}
$$


Sedangkan nilai premi tahunannya, yaitu:

$$
\begin{aligned}
\ddot{a}_{25: 5} & =\sum_{k=0}^{5-1} v_{k}^{k} p_{25}=4.16365 \\
P\left(\frac{A_{25: 5}}{\ddot{a}_{25: 5}}\right) & =\text { Benefit } *\left(\frac{A_{25: 5}}{\ddot{a}_{25: 5}}\right) \\
& =100 \text { juta }\left(\frac{0.56526}{4.16365}\right)=\text { Rp. 13,576,099 }
\end{aligned}
$$

Premi tunggal adalah besarnya premi yang dibayarkan secara total selama masa asuransi yaitu 5 tahun, yaitu sebesar Rp. 56.526.000. Sedangkan premi tahunan adalah besarnya premi yang dibayarkan tiap tahunnya, yaitu sebesar Rp. 13.576.099.

Nilai santunan (benefit) pada asuransi jiwa tradisional digunakan sebagai premi pada asuransi jiwa unit link. Sehingga perhitungan total lembar saham yang digunakan adalah sebagai berikut:

$$
\begin{aligned}
\text { Jumlah } \operatorname{Saham}(\mu) & =\frac{\text { Premi.Investasi }}{S(0)}=\frac{\text { Rp.100,000,000 }}{\text { Rp. } 1,410} \\
& =70,922 \text { lembar }
\end{aligned}
$$

Kemudian perhitungan premi tunggal bersih asuransi jiwa dwiguna unit link menggunakan metode annual ratchet digunakan Persamaan (7) dan (8). Sehingga diperoleh proporsi keuntungan optimum untuk metode compound ratchet sebesar $56.09 \%$ untuk nasabah dan 43.91\% untuk perusahaan asuransi. Sedangkan metode simple ratchet diperoleh proporsi keuntungan optimum sebesar $61.27 \%$ untuk nasabah dan $38.73 \%$ untuk perusahaan asuransi.

Tabel 1. Perbandingan Uang Santunan untuk Asuransi Jiwa Dwiguna Unit Link Menggunakan Compound Ratchet, Simple Ratchet, dan Investasi Biasa.

\begin{tabular}{cccc}
\hline Tahun & $\begin{array}{c}\text { Compound } \\
\text { Ratchet }\end{array}$ & $\begin{array}{c}\text { Simple } \\
\text { Ratchet }\end{array}$ & $\begin{array}{c}\text { Investasi } \\
\text { Biasa }\end{array}$ \\
\hline 2012 & Rp 100,000,000 & Rp 100,000,000 & Rp 100,000,000 \\
2013 & Rp 129,437,331 & Rp 132,155,913 & Rp 152,482,300 \\
2014 & Rp 135,346,747 & Rp 137,143,007 & Rp 108, 139,557 \\
2015 & Rp 155,264,491 & Rp 153,218,150 & Rp 126,236,584 \\
2016 & Rp 164,611,228 & Rp 159,793,978 & Rp 110,732,560 \\
\hline
\end{tabular}

Keuntungan investasi menggunakan metode compound ratchet pada akhir tahun 2016 sebesar Rp. 64,611,228 dengan proporsi keuntungan optimum sebesar 56.09\%. Sehingga proporsi keuntungan nasabah sebesar Rp. 64,611,228 $\times 56.09 \%=$ Rp. 36, 240,438 sedangkan proporsi keuntungan perusahaan asuransi sebesar Rp. 28,370,790.

Keuntungan investasi menggunakan metode simple ratchet pada akhir tahun 2016 sebesar Rp. $59,793,978$ dengan proporsi keuntungan optimum seebsar 61.27\%. Sehingga proporsi keuntungan nasabah sebesar Rp. 59,793,978 $\times 61.27 \%=$ Rp. 36,635,770 sedangkan proporsi keuntungan perusahaan asuransi sebesar Rp. 23,158,208. 


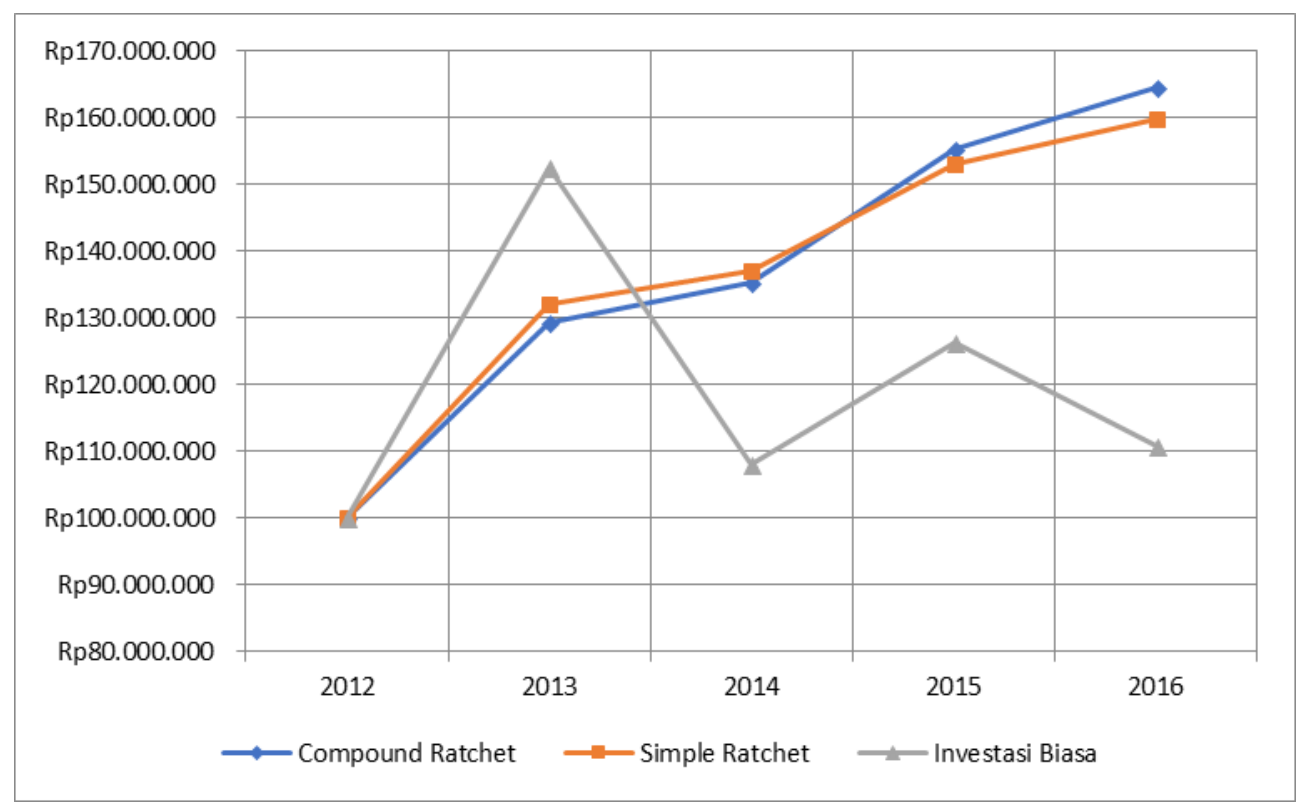

Gambar 1. Perbandingan Uang Santunan untuk Asuransi Jiwa Dwiguna Unit Link Menggunakan Compound Ratchet, Simple Ratchet, dan Investasi Biasa.

Berdasarkan Tabel 1 dan Gambar 1 terlihat bahwa pada tahun 2013 manfaat dengan menggunakan investasi biasa lebih besar dibandingkan dengan annual ratchet (compound dan simple). Sedangkan pada tahun berikutnya manfaat investasi dengan annual ratchet lebih besar dibandingkan investasi biasa. Hal ini dikarenakan nilai return pada tahun 2013 cukup besar sedangkan pada tahun berikutnya return mengalami penurunan dibandingkan tahun 2013.

Pada investasi biasa manfaat hanya membandingkan nilai saham tiap tahun dengan nilai saham pada tahun awal. Sedangkan pada annual ratchet manfaat dievaluasi dari tahun ke tahun (annual). Sehingga dari periode ke periode menjadi semakin besar yang merupakan akumulasi dari penambahan manfaat periode sebelumnya.

\section{KESIMPULAN}

a. Proporsi keuntungan optimum kontrak asuransi jiwa dwiguna unit link menggunakan desain compound ratchet sebesar 56,09\% untuk nasabah, dan $43.91 \%$ untuk perusahaan asuransi. Sedangkan untuk desain simple ratchet diperoleh proporsi keuntungan optimum sebesar $61,27 \%$ untuk nasabah, dan 38.73\% untuk perusahaan asuransi.

b. Proporsi keuntungan pada desain simple ratchet lebih besar dibandingkan dengan desain compound ratchet. Hal ini dikarenakan tingkat keuntungan pada compound ratchet lebih besar dibandingkan simple ratchet, akibatnya perusahaan juga menginginkan proporsi keuntungan (participation rate) yang lebih besar pada compound ratchet.

i. Keuntungan investasi menggunakan metode compound ratchet pada akhir tahun 2016 sebesar Rp. 64,611,228 dengan proporsi keuntungan 56.09\%. Sehingga proporsi keuntungan nasabah Rp. 64,611,228×56.09\% = Rp. 36, 240,438, dan proporsi keuntungan perusahaan asuransi Rp. 28,370,790.

ii. Keuntungan investasi menggunakan metode simple ratchet pada akhir tahun 2016 sebesar Rp. 59,793,978 dengan proporsi keuntungan 61.27\%. Sehingga proporsi keuntungan nasabah Rp. 59,793,978×61.27\% = Rp. 36,635,770, dan proporsi keuntungan perusahaan asuransi Rp. 23,158, 208. 


\section{DAFTAR PUSTAKA}

Fisk, E.R., 1997, Contruction Project Administration Fifth Edition. Prentice Hall, New Jersey.

Juliantari L. N., et al., 2017, "Premi Tunggal Asuransi Jiwa Seumur Hidup Unit Link Dengan Garansi Minimum dan Nilai Cap Menggunakan Metode Point-to-Point”. E-Jurnal Matematika., 6:22-28.

Hardy, M. R. 2006, “Invesment Guarantees: Modelling and Risk Management for Equity-Linked Life Insurance". USA: John Wiley and Sons, Inc.

Bowers, N. L., et al. 1997, "Actuarial Mathematics, Second Edition", The Society of Actuaries, United States of America.

Lin, X.S. and Tan, K.S., 2003, "Valuation of Equity-Indexed Annuities Under Stochastics Interest Rate", North American Actuarial Journal., 7:72-91. 